\title{
Formal opacity of derived lexemes as a factor motivating semantic change: The case of Ancient Greek nominals
}

\author{
Martin Masliš
}

(Charles University, Prague)

\begin{abstract}
This paper introduces synchronic formal opacity as a factor motivating semantic change on a par with cultural changes and pragmatic factors. The role of formal opacity in semantic change is investigated within the broader framework of lexicogenesis, i.e. the sum of processes that introduce new pairs of words and meanings in a linguistic system. In contrast to derivation, which introduces new pairs initially marked by formal and semantic transparency, semantic change can affect existing words that are formally and semantically opaque for those who acquire them. Opaque lexemes are described as unmotivated signs lacking a cue structure that would otherwise point speakers to the concepts labelled by them. This semiotic arbitrariness contrasts with motivated signs, that is morphologically transparent words that contain a recognized base morpheme cueing the concept they refer to. While focusing on this dichotomy in the lexicon of Ancient Greek, we argue that every novel derived word was initially motivated and contained a direct reference to the appropriate extra-linguistic concept. If a word ceased to be formally transparent, the motivation was lost, and the cue structure was effaced. The absence of cues enabled the acquirers to abstract any meaning reconcilable with the pragmatic context that, in turn, provided more space for semantic reanalysis. Besides this, semantic innovation effected by the speakers using words creatively was also influenced by the dichotomy between motivated and unmotivated signs. Whereas motivated words allowed speakers to exploit their structural and lexical semantics alike, the meanings of opaque words could be actively extended based only on their lexical semantics, since their structural meaning was inaccessible.
\end{abstract}

\section{Keywords}

semantic change; formal opacity; semiotics; Ancient Greek 


\section{Introduction ${ }^{1}$}

Research in historical linguistics distinguishes between the motivations for semantic change and its mechanisms. In a discussion about motivations, Traugott (2017) subsumes the causes of semantic change under two rubrics - changes in cultural discourse and pragmatic factors. The latter have received considerable scholarly attention as of late. In studies such as König \& Traugott (1988), Eckardt (2009), and especially Traugott \& Dasher (2002), pragmatics looms large and makes it possible to draw generalizations that strongly emphasize the role of interpersonal communication in the process of semantic change. In this approach, new word meanings arise and spread when speakers adopt the intended innovations of others or abstract the meaning of a word differently than was intended, usually by turning a contextual implicature into a general one. The immediate synchronic outcome in a language community is a polysemous lexeme, which may then undergo further development - see Hopper (1991: pp. 22-24) and Pustejovsky (1995: pp. 27-38). Individual word meanings may end up being subjectively so disparate that the synchronic situation can be described as homonymy rather than polysemy - see Valera (2020). If the historically prior meaning ceases to be current to the speakers, the diachronic perspective registers this as an instance of semantic change in a strict sense.

A slightly dissident view is put forward by Fortson (2003), who challenges some features of the pragmatic model as described in detail in Traugott \& Dasher (2002: pp. 24-40). The latter postulate some regularity in the process of semantic change, e.g., "external" meanings turning into more "internal" ones (feel 'touch' $\rightarrow$ 'think') or "objective" meanings coming to convey more "subjective" notions (Middle English pa hwile $p e$ 'at the time that' $\rightarrow$ concessive 'although'). Fortson deems these supposed clines to be epiphenomenal and pre-determined by the communicative contexts that invite one type of reanalysis more often than others. The types of reanalysis in agreement with the supposed regular patterns are simply more natural than those that would bring about a change in the opposite direction. As a more light-weight solution, Fortson proposes to structure theoretical accounts of semantic change around reanalysis itself. This process, in turn, is similar to the generalization of contextual implicatures mentioned above in that it assumes that new word senses arise in interactions between speakers. On the other hand, reanalysis does not imply an active mediation of word meaning between the acquirer and the speaker $\mathrm{s} /$ he is interacting with; in this framework, an innovation can sometimes stem from a mere misinterpretation.

In the present paper, we will focus on a hitherto understudied factor motivating semantic change, namely the synchronic formal isolation of lexemes. Discussion of the formal properties of words is not altogether absent from theoretical accounts. Hock (1991: pp. 296f.) lists sound change as one of the factors precipitating semantic change in that it helps obscure metaphorical meanings and imposes more concrete ones (e.g.,

1 This research is financially supported by the Charles University Research Centre program No. 204053 and the Charles University Grant Agency (GA UK), grant number 424420 "Semantic (in)stability of formally isolated lexemes exemplified on Ancient Greek" ["Sémantická (ne)stabilita formálne izolovaných slov na príklade starej gréčtiny”] awarded at the Faculty of Arts, Charles University. 
Old English daeges èage 'day's eye' > daisy). Heine et al. (1991: pp. 155-157) focus on the semiotic effect of this development. They use the term "bleaching", which deprives signs of their full semantic content, sometimes leading to grammaticalization. Such treatments, however, can be further elaborated by utilizing insights that stem from research in psycholinguistics.

Experimental data from modern languages suggest that derivationally related words interact in the mental lexicon and that the resulting networks, or families, influence lexical processing - see Diependaele et al. (2012: pp. 316-319) for a literature review and Sandell (2015: pp. 73-82) for a discussion of such effects in old Indo-European languages. In a language with complex concatenative morphology like Ancient Greek (henceforth AG), such synchronic families consisted of semantically related words that shared the same base morpheme in different derivations. In other words, speakers could incorporate words in their respective families based on formal and semantic criteria. Moreover, in languages with rich morphology, formal criteria alone are sometimes enough to ensure interaction between lexemes in the mental lexicon - see Boudelaa \& Marslen-Wilson (2015) on Arabic and del Prado Martín et al. (2005: p. 506) on Hebrew. This fact has consequences for the process of acquisition. Subjectively novel lexemes tentatively embedded in word families carry more cues as to their meaning because their lexical neighborhood supplies semantic hints. Accordingly, a statistical analysis of AG nominal lexemes in -po- and - $\mu$ o- in Masliš (forthcoming) shows that words built on formally transparent bases, and hence more likely to have been embedded in their respective families, were less likely to undergo a semantic change than their isolated counterparts built on synchronically opaque bases. This suggests that synchronic formal opacity facilitates semantic change. This effect is clearly morphological and cannot be explained in terms of pragmatics or sociolinguistics. The role of this factor is not strictly causal in that it would automatically trigger a change; it merely increases the likelihood. It is also not a necessary precondition, as semantic change can sometimes occur solely due to the other two factors.

In what follows, we will describe how the morphological effect of formal opacity motivated semantic change in AG. Furthermore, we will determine its relation to the established factors, that is pragmatics and cultural change. The notion of semantic reanalysis as described in Fortson (2003) will serve as a pragmatic backdrop instead of the more ambitious theory of invited inferencing developed in Traugott \& Dasher (2002).

\section{Motivation of linguistic signs and semantic cues}

The usual perspective in the study of historical semantics is that of semasiology. Here, lexemes represent the central part of the enquiry, which investigates what meanings these signs convey and how changes affecting word senses occur. For our purposes, the perspective opposite to that of semasiology, namely onomasiology, will serve as a point of departure. Onomasiological enquiry starts with real-world concepts and then proceeds to the realm of linguistic signs, studying how languages conceptualize extra-linguistic 
reality - see Glynn (2015: pp. 48f.) for a historical overview of this dichotomy with references. The onomasiological perspective naturally draws attention to the process of lexicogenesis, which introduces new pairs of word forms and word senses in a linguistic system - see Geeraerts (2010: p. 23).

The mechanisms of lexicogenesis include, among others, derivation, compounding, borrowing, ellipsis, truncation, root creation, but also semantic change. In order to explain the role of formal opacity in semantic change, we will investigate it not as an isolated phenomenon but in conjunction with another lexicogenetic mechanism - derivation.

Derivation in AG employed two strategies to create new lexemes: a) accentual and/ or apophonic shift; b) affixation. The former, also called internal derivation, was arguably less productive than in the protolanguage, but its outcomes are clearly traceable in the AG lexicon. Thus, for example, the relation between $* R(o)$-o- action nouns and $* R(o)$-ó- "possessives", that is nominals denoting possession of the verbal action, is that

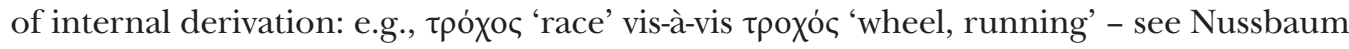
(2014a: pp. 243-251) and Nussbaum (2017: p. 239). Affixation, on the other hand, was exceptionally productive, building new lexemes by adding derivational affixes to roots, sometimes with a contrastive apophonic grade, or bases that could be themselves derived: e.g., $\psi \varepsilon \tilde{v} \delta$-oc 'lie' alongside $\psi v \delta$ - $\rho$ ó $\varsigma$ 'lying' or $\varepsilon ̋ \eta v$ 'stepped' (<* $\left.e-g^{z u} e h_{2}-m\right)$, whose root appears in the derived $\beta \tilde{\eta} \mu \alpha$ 'step' $\left(<* g^{z} e^{2} h_{2}-m n\right)$, which gave rise to $\beta \omega \mu$ ó ‘ 'altar, platform’ (<* $\left.g^{\text {sw }} \mathrm{Oh}_{2}-m(n)-o^{-}\right)$- see Beekes (2010: pp. 1663, 251).

Every derived word is formally transparent at the time it is coined. In other words, speakers register its morphemic make-up, which enables them to class the word with its relatives or the derivational source. The other component of the lexicogenetic process is the assignment of a word sense so that a real-world concept finds an adequate expression in the linguistic system. Given that new derived lexemes recycle existing morphemes or patterns that already convey meanings, the new form by default conveys a structural sense that stems from the semantics of the word constituents. Thus, the structural sense of the adjective $\psi v \delta$ - $\rho$ ó $\varsigma$ emerges as a conjunction of the root $\psi(\varepsilon) v \delta$ - 'tell a lie' and the adjectival suffix - $\rho$ ó-.

The structural sense, however, does not always accurately predict the actual lexical sense. ${ }^{2}$ For instance, amphikinetic nominals in $-\mu \omega v$ (formally $* R(\hat{e})-m o n-E(\varnothing) /{ }^{*} R(\varnothing)-m n$ $\left.E\left(e^{\prime}\right)\right)$ internally derived from proterokinetic deverbatives in $-\mu \alpha$ (formally ${ }^{*} R(\hat{e})-m n /{ }^{*} R(\emptyset)$ mén-) can denote instantials (nomen rei actae) or agents: e.g., $\theta \tilde{\eta} \mu \alpha$ 'tomb' ( $\leftarrow$ '*piling') $\rightarrow$ $\theta \eta \mu \omega \dot{\omega}$ 'heap' but $\gamma v \tilde{\omega} \mu \alpha$ 'thought' $\rightarrow \gamma \nu \omega \dot{\omega} \mu \nu v$ 'expert, pointer' - see Nussbaum (2014a: pp. 248-251). These discrepancies did not necessarily have to arise after prolonged semantic development, but could have been present right from the moment these lexemes were coined. Nevertheless, unpredictability of the lexical sense measured against the struc-

2 The distinction of structural versus lexical sense is a staple of the onomasiological theory of word formation developed in Dokulil (1962), which attracted a considerable following in Central and Eastern Europe. The discussion concerning the dichotomy at hand can be found in Dokulil (1962: pp. 94-102) and Dokulil (1978), and a summary of Dokulil's theory in English is available in Štekauer (2005a: pp. 209-211). Štekauer (2005b: pp. 1-42) presents an overview of literature on the semantic predictability of new coinages. 
tural meaning did not preclude speakers, at least initially, from registering connections between related words, as the following lemmas from the Etymologicum Magnum ${ }^{3}$ show.

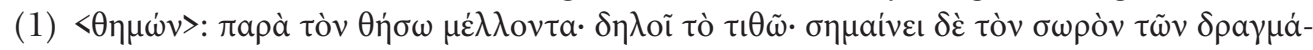
$\tau \omega v$.

' $\langle\theta \eta \mu \omega \nu>$ : from the future tense $\theta \dot{\eta} \sigma \omega$, which means 'put'; it denotes a bunch of stalks.' (EM 451.8)

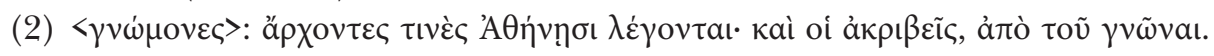
' $\langle\gamma \nu \omega \dot{\mu} \mu \nu \varepsilon \varsigma\rangle$ : the name of some officials in Athens; also, those who are precise; it comes from $\gamma v \tilde{\omega} v a ı$ 'know'.' (EM 236.57)

Such derived lexemes, considering their sense at the time of their coining, are motivated. ${ }^{4}$ That is, a particular triad of a form, a word sense, and a real-world concept is not arbitrary from the perspective of other lexemes that share the same derivational base. For instance, the form $\gamma \nu \omega \mu \omega \nu$ denoting the concept KNOWLEDGEABLE PERSON was synchronically motivated because the speakers were aware that a particular feature of the concept - being knowledgeable - was expressed through the morpheme $\gamma v \dot{\omega}-$. The semantic contribution of the base morpheme, in turn, was made perspicuous thanks to other lexemes sharing the same root and expressing cognitively related concepts, e.g., $\gamma \nu \tilde{\omega} v a ı$ 'know'. The examples from the etymologica cited above confirm this analysis.

The onomasiological insight in the case of derived words is that an innovative speaker selects a source morpheme from the inventory based on the salient feature of the concept s/he wants to express. Even though every concept has many features that could motivate a base morpheme, the one that finds an exclusive linguistic expression in the label then determines how speakers cognitively grasp the concept. For instance, the word $\gamma \nu \omega \dot{\mu} \mu \nu$ denotes a KNOWLEDGEABLE PERSON through the feature of KNOWING, which is captured by the root $\gamma v \omega$-. This state persists as long as speakers are able to identify the derivational base and find a plausible reason why a particular concept should be marked by the feature denoted by the morpheme. The obstacle caused by the fact that lexical sense is not always a priori predictable nor strictly construable is alleviated in several ways. First, the structural sense of a word is always specified by its apparent referent. Since speakers encounter new words embedded in a communicative context, semantic input is available from both the linguistic system and extra-linguistic reality. Second, speakers rely in their subjective analysis on encyclopedic world knowledge. This allows them to establish connections between related words, even if a derived lexeme displays

3 A mid-12 $2^{\text {th }}$ cent. lexicographical work based on earlier etymologica like the Etymologicum Gudianum (the $10^{\text {th }}$ cent.), the Etymologicum Genuinum (the $9^{\text {th }}$ cent.), and Orion's Etymologicum (the $5^{\text {th }}$ cent.) - see Alpers (1990: pp. 27-32) and Reitzenstein (1905: pp. 15-16). The sources generally date to the $2^{\text {nd }}$ cent. CE and later, but as these works utilized even earlier Hellenistic scholarship, some of the material may ultimately derive from the period when a variety of Greek close to the classical Attic dialect was spoken - see Dickey (2015: p. 472).

4 The notion of motivation, applied especially in the description of derived words, was well established in the structuralist works of the scholars associated with the Prague linguistic circle, e.g. Mathesius (1966: pp. 14-16). Dokulil (1962: pp. 103-117) and Furdík (1993) further elaborated it in their accounts of word formation in Czech and Slovak. 
rather specific semantics compared to its source. Thus, the analytic flexibility often helps

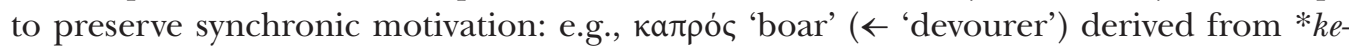
$h_{2} p$ - 'take' is analyzed correctly as related to кá $\tau \tau \omega$ 'gulp down' in EM 234.31 - see also Beekes (2010: pp. 639f.).

These characteristics of synchronically motivated words affect the acquisition of semantics. Masliš (forthcoming) argues that AG speakers exposed to a novel derived word that was morphologically analyzable identified its base and matched it with other lexemes sharing the same base. If possible, the referent of the newly acquired word was then conceptualized through the feature which was expressed by the derivational base. For example, the word $\gamma \nu \omega \dot{\omega} \omega \nu$ acquired with the sense 'expert' was conceptualized as 'the knowing one' if the speaker realized there was a connection to $\gamma v \tilde{\omega} v a \mathrm{l}$ 'know' and deemed this connection plausible.

Consequently, synchronically motivated words impose a specific type of connection between the sign and the referent. Even though the referent that warrants the appropriate sign usually possesses many features, only one of them is independently sanctioned by the linguistic system - the one coded by the base morpheme, which appears in other related words. This does not imply that a transparent base is monosemous across a word family, but rather underspecified. Its precise input is specified on the level of individual derivations. Viewed from the semasiological perspective, this structure can be expressed as a relation of one to many through one: one label refers to a concept, which has many features, but only one of them is constantly evoked by the sign itself. The feature RELATED TO KNOWLEDGE would then be a better predictor of the label $\gamma \nu \dot{\omega} \mu \omega \nu$ than the feature PROVIDING ADVICE, although the latter would appear quite often alongside the former with the referents of the AG word.

Lexemes that were synchronically opaque and could not be analyzed lacked this semiotic structure. The relation between an unmotivated sign and a concept within individual mental lexicons could be described as one to many: one label refers to a concept, which has many features. Even though some of the features are salient and predict the label more accurately than the others, none of them is clearly encoded by the sign itself. ${ }^{5}$

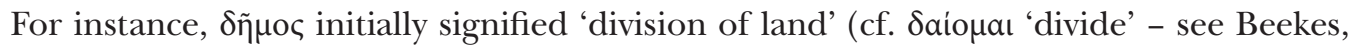
2010: p. 325) before it was metonymically extended to mean 'commoners' and ultimately 'the people' in the political sense. The extension is easier to be reckoned with if we suppose that the label $\delta \tilde{\eta} \mu$ o with the word sense 'division (of land)' lost the cue structure that would otherwise point speakers to the feature that initially motivated this derivate to

5 Cf. Ramscar et al. (2010: pp. 917f.): "Verbal labels are relatively discrete and possess little cue structure - by 'cue structure' we mean the number of salient and discriminable cues they present simultaneously - whereas objects and events in the world are far less discrete and possess much denser cue structure. Consider a situation in which a PAN is encountered in the environment. A PAN has many discriminable features a learner might treat as cues to PAN, namely its shape, color, size, and so on. Now consider the label pan. A native English speaker can parse it into a sequence of phonemes $\left[\mathrm{p}^{\mathrm{h}}\right.$ an] but will be largely unable to discriminate further cues within these sounds. (...) When a label such as pan serves as a cue, it essentially provides a learner with a single useful cue: the label pan itself." In our opinion, this holds only for unmotivated labels. Motivated words possess a cue in the form of their base morpheme, which appears in other words. 
be used as a sign for that particular concept, namely a DIVISION OF A WHOLE. Given the synchronic arbitrariness of such signs referring to real-word concepts, the perception of the features that predict the label can shift more easily than in the case of motivated words, which are endowed with internal cues sanctioned by synchronically related lexemes. Again, the lemma in the Etymologicum Magnum illustrates that speakers failed to identify the onomasiological motivation for the sense 'the people'; the same was very probably the case for the sense 'division of land' even with the earliest occurrences in the epics.

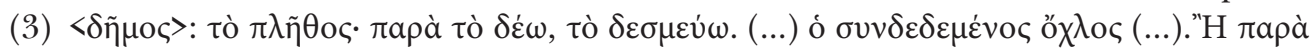

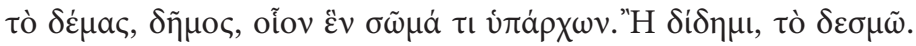

' $\langle\delta \tilde{\eta} \mu о \varsigma>$ : a multitude; it comes from $\delta \dot{\varepsilon} \omega$ 'unite' and refers to the united people. Alternatively, it could come from $\delta$ '́naৎ 'a human body', as if it signified some-

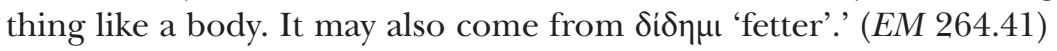

\section{Semasiological motivation and its loss}

Before we proceed to the discussion of semantic change, the factors that help efface synchronic motivation of linguistic signs need to be addressed. As stated above, speakers could perceive a sign as motivated only if they recognized its base morpheme and deemed its semantic input reconcilable with the referent. Common empirical tests that measure whether and to what extent speakers register relations between cognate words are not applicable on corpus data. Nevertheless, indirect evidence can reveal the scope of synchronic word families and hence single out lexemes that were isolated and unmotivated. We have already mentioned the etymologica, which are a good approximation of how native speakers of Hellenistic and late antique varieties of Greek processed word networks. Incorrect etymologies therein indicate probable isolation and no available motivation. Further hints can be obtained by studying word collocations. The employ-

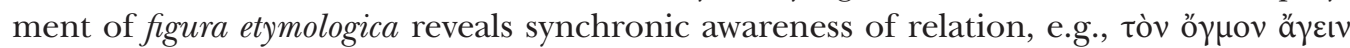
(Theoc. 10.2) 'mow swathes (of corn)', where both terms stem from * $h_{2} e g$ - 'drive'. Collo-

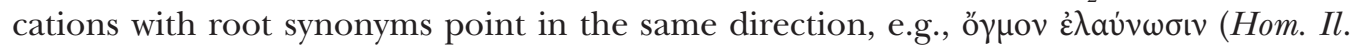

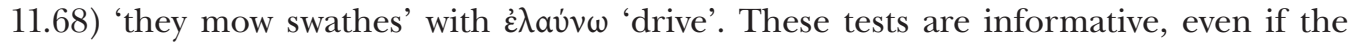
lexical sense does not straightforwardly stem from the structural one. With words whose meanings are more predictable, formal identity of the base and semantic closeness are good predictors of family effects in the mental lexicon, as is befitting of a language with complex morphology (see references regarding Arabic and Hebrew in the Introduction).

Awareness of relation could be hampered by uncanonical alternations caused by sound changes, which were context-sensitive and synchronically unpredictable. For in-

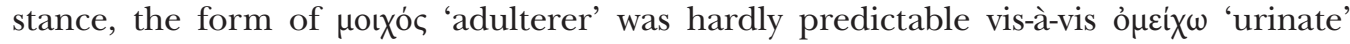
thanks to the Saussure effect $\left(* h_{x} R o C_{-}>* R o C-\right)$, even though both forms stem from the root *h $h_{3} m e y \hat{g}^{h}$ - 'urinate' - see Rix \& Kümmel (2001: pp. 301f.); an incorrect etymology is supplied by EM 589.35. Other factors operating on the formal plane had in common the fact that they obfuscated the regularities that would otherwise enable the speakers to match words with their relatives. Thus, loss of productivity of some morphophonemic 
patterns, often coupled with sound changes, sometimes rendered their inherited outcomes formally disparate. The waning of internal derivation belongs under this rubric. Another contributor to diminished transparency were the formal properties of some roots. Greek radicals with fewer phonemes offered fewer cues as to the identity of the base morpheme. The root $\varepsilon \dot{l}-\left(<{ }^{*} h_{1} e y-\right.$ 'go'), for example, consists of a single phoneme, which provides fewer indices than a triconsonantal root like $\varphi \varepsilon \rho-\left(<* b^{h} e r\right.$ - 'bear'). Conse-

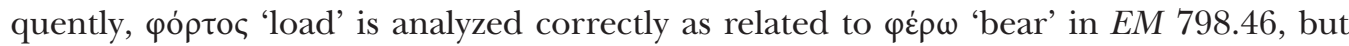
oĩ the lexicographer in $E M$ 619.27. Also, words with no surviving relatives whatsoever were naturally isolated. All these aforementioned factors could combine and sometimes result in the synchronic opacity of a lexeme or its base, which, in turn, cancelled semasiological motivation.

After being recognized, a base could supply meaningful semantic cues only if it was reconcilable with the apparent referent of a derived word. Here, the domain of culture crosses over into the domain of cognition. An onomasiological motivation that led to a particular derivation being coupled with a specific lexical sense might have been apparent for the speaker who coined the word, but others might not have seen the connection, or it could have been lost gradually due to cultural changes. Accordingly, a label for a referent conceptualized through its salient feature, a relation of one to many through one, lost its internal cue structure and a relation of one to many ensued. For instance, the word poppós is used in the sense 'basket' (e.g., in Hesiodus, Herodotus, and Polybius), 'plaited mat' (e.g., in Herodotus, and Aristophanes), and 'coarse cloak' (e.g., in Theocritus, and Pausanias). The derivation most likely contains the root $* b^{h} e$ 'bear', as the oldest attested sense suggests - see Chantraine (1968-1980: p. 1222). The initial motivating feature BEARING agrees with the sense 'basket', but the other two senses diverge. A likely explanation is that the speakers who extended the sense to 'mat' and 'coarse cloak' perceived the feature PLAITED, a common quality of wicker baskets, as more salient. The onomasiological connection between $\varphi$ opuó ` 'basket' and its two later senses was facilitated by a feature that is not encoded in the label. Outcomes of such semantic extensions are not sanctioned by the linguistic system and the resulting word senses are unmotivated. It perhaps follows that the speakers who innovated were not particularly aware of the motivating feature behind the original sense despite the formally transparent base.

It is also possible that the semantics of high-frequency words were processed differently than those of low-frequency ones. In the domain of morphology, Bybee (1985: p. 124) claims that low-frequency items are analyzed in terms of other items, while high-frequency words are processed unanalyzed, see also Schreuder \& Baayen (1995: pp. 151f.) and, for AG, Probert (2006). Carrying this approach to semantics, common words, even the formally transparent ones, would evoke a concept as a whole, while rare words would favor the reading of one to many through one. In English, for instance, computer is often conceptualized as 'an electronic device which is used to store, manipulate, and communicate information', but sanitizer is understood as 'a substance which sanitizes', see Oxford English Dictionary, s. v. computer and sanitizer. 


\section{Semantic change: different paths of motivated and unmotivated lexemes}

Standard treatments of semantic change acknowledge that a path from a word sense A to a word sense B recorded at a later diachronic stage most often leads through a phase when both meanings coexist within a community, and the word is polysemous: $\mathrm{A} \rightarrow \mathrm{A}+\mathrm{B} \rightarrow \mathrm{B}$. The categories of change that define the relation of a meaning $\mathrm{B}$ to a source meaning A are similarly well mapped and a standard classification is as follows: metaphoric extension, metonymic extension, pejoration, amelioration, narrowing, and generalization - see Campbell (2013: pp. 222-232), Fortson (2003: pp. 648-650), and Traugott (2007). Moreover, it is possible to differentiate whether a new contextual meaning B arose because a speaker had used a word usually signifying A in a novel way or because an addressee had misunderstood a speaker who, to his mind, had used a word in its usual sense A.

Strictly speaking, a word is said to have undergone a semantic change when the older meaning A ceases to be current to the speakers, which are aware only of the meaning B. Effacement of the word sense A in a language community ensues when the individual speakers fail to acquire the word with this sense. This step is facilitated by reanalysis on the side of the acquirers, who either understand the intended sense $\mathrm{A}$ as $\mathrm{B}(\mathrm{A} \rightarrow \mathrm{B})$ or fail to notice that the intended sense $B$ is just a contextual extension, e.g. a metaphor, of $A$ and they abstract the word sense exclusively as $B(A \sim B \rightarrow B)$.

The role of formal opacity can be isolated and studied at two different stages of the scheme $\mathrm{A}(\rightarrow \mathrm{A} \sim \mathrm{B}) \rightarrow \mathrm{B}$. First, it involves the part $\mathrm{A} \rightarrow \mathrm{A} \sim \mathrm{B}$, which concerns the speakers who employ a word meaning A creatively so that it contextually means B. Second, formal opacity influences the part $\rightarrow \mathrm{B}$, which effaces the meaning A through reanalysis. Effects of opacity, to our mind, are clearer at the stage of reanalysis that results in the meaning B being acquired as the sole available word sense of a lexeme in an individual mental lexicon. Here, any reanalysis is a discrete moment grounded in inter-personal communication. The definition of syntactic reanalysis formulated in Langacker (1977: p. 59) describes it as a change in the structure of an expression that does not immediately affect its surface manifestation. This also holds true in the domain of semantics: an acquirer abstracts a different semantic structure of a lexeme from a communicative context; the surface manifestation remains intact because the participants of the communication do not register any deficiencies or infelicities. The acquirers are free to abstract any word sense that fits the context at hand. This transfer of individual grammars and lexicons naturally entails imperfections, that is loss of information or its restructuring - cf. Fortson (2003).

We have described formally opaque words as unmotivated and their semiotic structure as one to many, with one label referring to a concept with many features. In contrast to motivated words, no feature of the referent is independently captured by its label. Loss of motivation, consequently, is the smallest change that can affect a word sense during transfer of lexical items among speakers. The set of features predicting a label can remain the same, but the motivating feature synchronically loses a privileged 


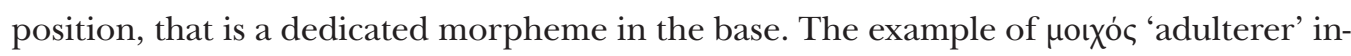
troduced above belongs here. At one discrete moment, an acquirer failed to realize that

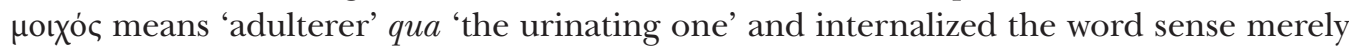
as 'adulterer'. At some point, this analysis came to prevail in the language community.

The discontinuity of transmission can naturally lead to a different set of predicting features being abstracted. With no cues present in the label, the initial motivating fea-

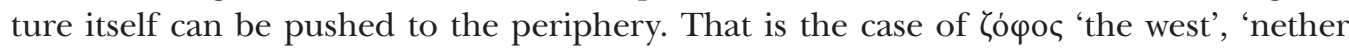
darkness', and 'darkness'. Janda (2000: pp. 205f.) identifies the etymon as an action noun *yó $b^{h}-o$ - from the root *yeb $b^{h}$ 'enter', 'have intercourse'. The abstract sense of the root is attested in Hittite and Tocharian, while the specialized meaning of its Slavic and Indic derivates points to a semantic extension of PIE date - see Rix \& Kümmel (2001: p. 309).

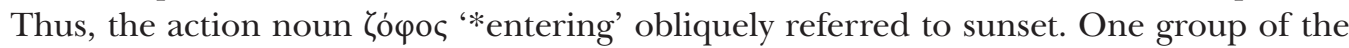
Homeric occurrences refers to 'the west' (Il. 12.240, Od. 9.26, Od. 10.190, Od. 12.81, Od. 13.241). Another group of the occurrences can be interpreted as 'darkness', but it is the

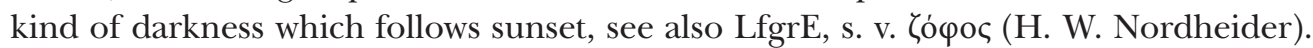

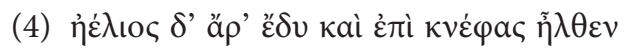

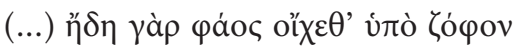

'And the sun set, and darkness came on... Even now has the light gone down beneath the darkness'. (Od. 3.329, 335, transl. Murray 1919)

The sense 'nether darkness' in (5) a. is likewise juxtaposed to the disappearance of the sun. In a similar vein, example (5) b. shows that one could approach the Netherworld by going west.

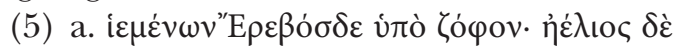

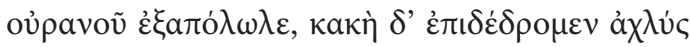

'(Ghosts of the suitors) that hasten down to Erebus beneath the darkness, and the sun has perished out of heaven and an evil mist hovers over all.' (Od. 20.356-357, transl. Murray 1919)

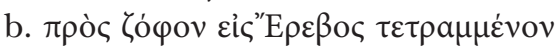

'(The cave of Scylla) turned to the west, toward Erebus.' (Od. 12.81, transl. Murray 1919)

It is safe to assume that the speakers of the time did not know which feature initially

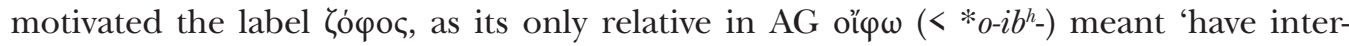
course' and could hardly appear to be related. ${ }^{6}$ Nevertheless, all the Homeric occurrences are still connected to the concepts related to the disappearance of the sun. This early semantic inertia shows that a loss of motivation does not automatically entail a distur-

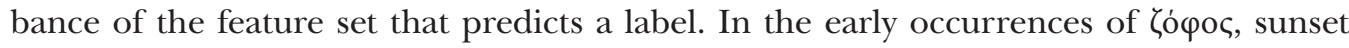

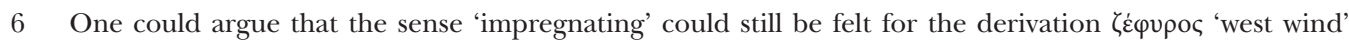
because Hom. Il. 16.149-151 mentions that the horses Xanthus and Balius were sired by Zephyrus with the harpy Podarge. However, the north wind god Boreas appears in the same role in Hom. Il. 20.219-225, siring twelve foals with the mares of Erichthonius. The motif of conception from wind appears in other folk traditions throughout the world - see Thompson (1955-1958), Motif T524. 
remains present. The subsequent path of the word reveals that the initial motivating

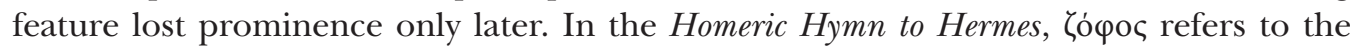
darkness of a cave.

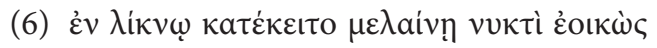

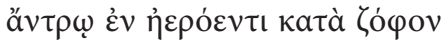

'(Hermes) lay down in his cradle in the gloom of a dim cave, as still as dark night.' (h. Hom. Mer. 358-359, transl. Evelyn-White 1914)

Occurrences in prose likewise mean 'darkness' regardless of its origin.

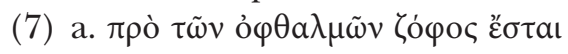

'There will be darkness in front of one's eyes.' (Hp. Mul. aff. 8.18)

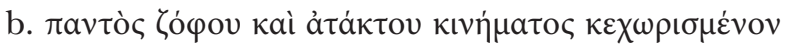

'(Mount Olympus) not affected by any darkness nor irregular movement (...)' (Arist. Mund. 400a.9).

Another example illustrating this process is the adjective $\varepsilon \sigma \theta \lambda$ ó $\varsigma$ 'good', which belongs in the poetic register. Nussbaum (2014b: 248-250) posits an initial verbal abstract $* h_{1} e ́ s-d^{h} l o$ - 'wherewithal' from the root $* h_{1} e s-$ 'be'. Its internal possessive derivation * $h_{1} e s$ $d^{h} l o ́$ - would have meant 'having wherewithal'. The original locus of the adjective was in describing well-off individuals; thus, a reanalysis resulting in the sense 'good' is unproblematic. The etymological sense was lost early, as the adjective appears in collocations with humans, animals, physical items, and abstracts in the epics. The lemma EM 383.7 does not contain the correct etymology, nor a correct segmentation in $\dot{\varepsilon} \sigma-$ and $-\theta \lambda_{\mathrm{o}}$ Interestingly, a comparable derivation $\gamma \varepsilon v \varepsilon \dot{\varepsilon} \theta \lambda \eta$ 'birth(day), family' is segmented correctly in $\gamma \varepsilon v \varepsilon$ - and $-\theta \lambda \eta$, and its base is matched with other words containing the root $*^{\prime} e n h_{1-}$ 'beget, conceive' in EM 225.20. The formal properties of the base $\varepsilon \sigma-$, which is short and contains an instable - $\sigma$ - (cf. عivval 'to be'), could have contributed to the semantic development of $\dot{\varepsilon} \sigma \theta \lambda$ ó, which is lexically isolated.

Changes in sets of features predicting a label are conspicuous in the case of words that were transmitted only within the poetic tradition. The limited number of occurrences eases the task of locating the bridging context. For instance, the elusive Homeric adjective ááatoৎ was ingeniously analyzed as *n-sh $h_{2} w n-t o-$ 'not lit by the sun' in Nikolaev (2012/2013). This form is a derivation of a PIE heteroclitic noun *séh ${ }_{2} w l / s h_{2} w e ́ n$ - 'sun',

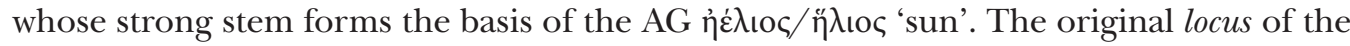
epithet was an oath with a reference to the underworld river Styx.

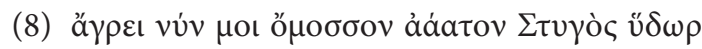

'Come on and swear to me by the sunless waters of Styx.' (Il. 14.271)

Authors of later epic passages and Apollonius Rhodius, however, used the word in the broad sense 'sinister' or 'deadly'.

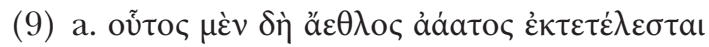

'This deadly contest (with the suitors) is at an end.' (Od. 22.5)

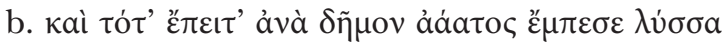




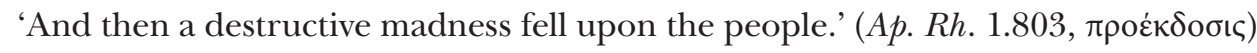

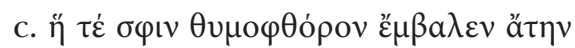

'(Aphrodite,) who sent upon them a soul-destroying blindness.' (Ap. Rh. 1.803, vulgata)

Two variants of the same line in Apollonius ${ }^{7}$ with nearly identical content reveal that the author understood the epithet as synonymous to $\theta v \mu \circ \varphi \theta$ ópoc 'soul-destroying' and connected to ätๆ 'delusion' - see Nikolaev (2012/2013: pp. 197f.), including a discussion of the remaining occurrences in the Odyssey and the Argonautica. With these examples, a reanalysis of the original context from Il. 14.271 explains the later usage better than, say, a metonymic shift. Possibly, the word meaning 'sunless' offered no internal cues at the time the oath formula was composed or included in the poem. This was certainly the case for the later author of the Odyssey passage in (9) a. and Apollonius Rhodius, who had to abstract the meaning of the epithet purely from the context.

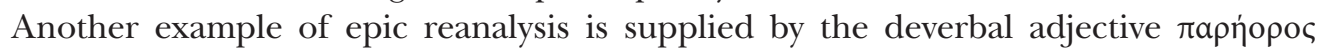
with the etymological sense 'joined beside' - see Tichy (1983: pp. 366f.) on the history of the verbal forms related to the passive aorist $\pi \alpha \rho \eta \dot{\varepsilon} \rho \theta \eta$ 'hang on one side'. In Hom. Il. 16.466-475, the adjective applies to the trace-horse Pedasus, which is slain by Sarpedon. The remaining two horses of the team are startled, 'as the trace-horse lies low in the

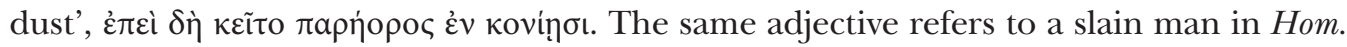

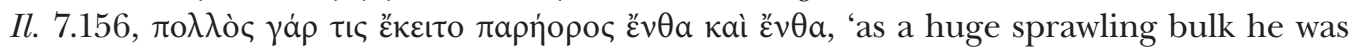
lying stretched this way and that'. The author of this passage abstracted the meaning 'sprawling' from the Pedasus episode, where it means 'trace-horse'. The same sense of the adjective appears later in Aeschylus, referring to the immobilized body of Typhon (Aesch. Pr. 365).

Note that opaque or unmotivated lexemes afford the acquirers more freedom to make any sense of what has been said or written. An arbitrary word can be understood this way or that as long as the communication makes sense. Recasting the debate in terms of analytic freedom also has some bearing on the stage $A \rightarrow A \sim B$, when speakers actively innovate rather than analyze. Changing the perspective to motivated words, let us observe how morphological and semantic transparency guides the process of active semantic extension.

When speakers use a familiar word in a novel way, a feature of the original referent A facilitates a link with a new concept $\mathrm{B}$, which is then contextually labeled by a sign usually signifying A. If the contextual meaning B sticks, an implicature changes to an entailment, which, in turn, can sometimes survive while the older meaning A vanishes. The second stage belongs in the domain of reanalysis, which has been dealt with above and will not concern us now. Let us turn now to the stage of innovation: Employing a synchronically motivated word creatively would be influenced by its transparent base pointing to a particular feature. Save for irony, speakers aware of the motivation would

7 The reading from (9) b. is preserved in scholia $L$ in an excerpt, the source of which the scholiast labels as

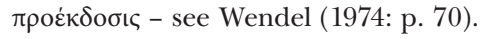


tend not to use a word in a way which would break the meaningful link between the base morpheme and the new concept in need of a fitting label. The familiar example of $\gamma \nu \omega \mu \omega \nu$ provides a few instances of such extensions. The feature RELATED TO KNOWLEDGE or RELATED TO INFORMATION persists in all the senses listed sub voce in LSJ. These include, among others, the senses 'interpreter' (Aeschylus), 'expert' (an Iasus inscription from the $4^{\text {th }}$ cent. BCE), 'carpenter's square' (Polyaenus), 'pointer of the sun-dial' (Herodotus), 'teeth that mark a horse's age' (Xenophon), and 'rule of life' (Theognis). The relevant lemma in the Etymologicum Magnum, which safely establishes a connection with $\gamma v \tilde{\omega} v a \mathrm{t}$ 'know', lists the senses 'measuring rod', 'geometrical figure', 'part of optical and astronomical instruments', 'pointer of the sun-dial', and 'Athenian officials' - see EM 236.54. It is quite improbable that these meanings arose through reanalysis on the side of the acquirers. It is rather the speakers who took advantage of the structurally perspicuous lexeme and used it creatively. This pattern of polysemy reveals that the speakers extended the sense domain based on the structural semantics of the lexeme which rested upon the feature coded by the base $\gamma \nu \omega \dot{-}$. Thus, the linguistic system itself, characterized by the interconnectedness of related items, plays an important role in semantic extensions that concern synchronically motivated and transparent words.

Isolated and hence unmotivated lexemes do not display the same pattern of active semantic innovation. The fact that none of the features predicting an unmotivated label is incorporated in the label itself means that the creative use of the label must be facilitated by a feature of the concept it refers to. Note that in the case of motivated lexemes, the source of extension could be in the linguistic system, i.e. a base morpheme sanctioned by other related words. With unmotivated words, the source is necessarily lodged in the extra-linguistic reality, namely a concept currently denoted by the label at hand. Let us return to the example of $\delta \tilde{\eta} \mu о \varsigma$. The metonymic extension 'region' $\rightarrow$ 'commoners, inhabitants' is not based on the etymological meaning of the root $\delta \tilde{\eta}$ - 'divide', since this analysis was most likely synchronically unavailable, but on the concept REGION, i.e. a section of the extra-linguistic reality denoted at that time by the label $\delta \tilde{\eta} \mu \circ \varsigma^{\prime}$ 'region'. In other words, the source concept or the source feature is accessible only through the lexical semantics of the unmotivated label, whereas motivated words afford two possible ways to access the source - structural semantics (e.g., $\gamma \nu \dot{\omega}$ - 'related to knowledge' in $\gamma \nu \omega \dot{\omega} \mu \nu \rightarrow$ 'expert', 'pointer of the sun-dial', etc.) and lexical semantics (e.g., $\gamma \nu \omega \dot{\omega} \mu \nu v$ 'expert' $\rightarrow$ 'an Athenian official').

\section{Conclusion}

We have attempted to demonstrate that the notion of synchronic isolation has its place in the account of semantic change. In a language with complex concatenative morphology and prolific patterns of derivation like Ancient Greek, related words formed families which influenced lexical and semantic processing. Semantics of derived words that participated in such networks were structurally sanctioned by related words that shared the same base morpheme. Moreover, these words included a direct reference to the feature 
that initially motivated the connection between a label and a particular concept. The semiotic structure of such signs can be described as a relation of one label referring to a concept with many features through one salient feature. On the other hand, derived lexemes that were isolated were synchronically unmotivated and semiotically arbitrary. They likewise referred to concepts with many features, but none of them was encoded in the label itself.

This semiotic difference influenced the ways words changed their meaning. The smallest change that could affect a word semantically was the loss of motivation - the motivating feature ceased to be perceived as directly encoded by the label. This occurred either due to formal and exclusively linguistic reasons, i.e. formal opacity, or because of cultural changes. Unmotivated lexemes with no internal cues were more prone to undergo a change that alters the set of conceptual features that predict a label. This happened through semantic reanalysis when acquirers abstracted a different lexical meaning compared to the one their interlocutors ascribed to the sign. Transparent words, on the other hand, always contained a reference to at least one conceptual feature, which limited the space for reanalysis, provided that the acquirers recognized the derivational base and deemed it compatible with the apparent referent of a novel word they had encountered.

Formal isolation also affected how speakers creatively innovated the semantic ranges that a word could cover. Unmotivated words provided no access to their structural meaning and the speakers using them innovatively could rely only on their lexical meaning as a source domain for new applications. Transparent words, on the other hand, offered two paths to the features that could form a bridge to a new concept - first, structural meaning, i.e. the semantic field constructed around a transparent base morpheme, and second, the lexical meaning of the source lexeme as a whole.

\section{Bibliography}

Allen, T. W., Halliday, W. R., \& Sikes, E. E. (Eds.). (1936). The Homeric hymns (2nd ed.). Oxford: Clarendon Press.

Alpers, K. (1990). Griechische Lexikographie in Antike und Mittelalter. In H. Koch, \& A. KrupEbert (Eds.), Welt der Information (pp. 14-38). Stuttgart: Metzler.

Beekes, R. (2010). Etymological dictionary of Greek (2 Vols.). Leiden - Boston: Brill.

Boudelaa, S., \& Marslen-Wilson, W. D. (2015). Structure, form, and meaning in the mental lexicon: Evidence from Arabic. Language, Cognition and Neuroscience, 30(8), 955-992.

Bybee, J. L. (1985). Morphology: A Study of the Relation between Meaning and Form. Amsterdam Philadelphia: Benjamins.

Campbell, L. (2013). Historical linguistics ( $3^{\text {rd }}$ ed.). Edinburgh: Edinburgh University Press.

Chantraine, P. (1968-1980). Dictionnaire étymologique de la langue grecque: Histoire des mots. Paris: Klincksieck.

del Prado Martín, F. M., Deutsch, A., Frost, R., Schreuder, R., De Jong, N. H., \& Baayen, R. H. (2005). Changing places: A cross-language perspective on frequency and family size in Dutch and Hebrew. Journal of Memory and Language, 53(4), 496-512. 
Dickey, E. (2015). The sources of our knowledge of ancient scholarship. In F. Montanari, S. Matthaios, \& A. Rengakos (Eds.), Brill's Companion to Ancient Greek Scholarship (2 Vols.; pp. 459514). Leiden - Boston: Brill.

Diependaele, K., Grainger, J., \& Sandra, D. (2012). Derivational Morphology and Skilled Reading: An Empirical Overview. In M. J. Spivey, K. McRae, \& M. F. Joanisse (Eds.), The Cambridge Handbook of Psycholinguistics (pp. 311-332). Cambridge: Cambridge University Press.

Dokulil, M. (1962). Tvoření slov v češtině I. Teorie odvozování slov. Praha: Nakladatelství Československé akademie věd.

Dokulil, M. (1978). K otázce prediktability lexikálního významu slovotvorně motivovaného slova. Slovo a slovesnost, 39, 244-251.

Eckardt, R. (2009). APO: Avoid pragmatic overload. In M. Hansen, \& J. Visconti (Eds.), Current trends in diachronic semantics and pragmatics (Studies in Pragmatics, 7; pp. 21-41). Bingley: Emerald Publishing.

Evelyn-White, H. G. (Ed. \& Transl.). (1914). Hesiod. The Homeric hymns, and Homerica. London: W. Heinemann.

Fortson, B. W. (2003). An approach to semantic change. In R. D. Janda, \& B. D. Joseph (Eds.), The Handbook of Historical Linguistics (pp. 648-666.). Malden - Oxford - Melbourne - Berlin: Blackwell.

Fränkel, H. (Ed.). (1986). Apollonii Rhodii Argonautica. Oxford: Clarendon Press.

Furdík, J. (1993). Slovotvorná motivácia a jej jazykové funkcie. Levoča: Peter Modrý.

Gaisford, T. (Ed.). (1848, repr. 1967). Etymologicum Magnum. Oxford: Oxford University Press.

Geeraerts, D. (2010). Theories of lexical semantics. Oxford: Oxford University Press.

Glynn, D. (2015). Semasiology and onomasiology. In J. Daems, E. Zenner, K. Heylen, D. Speelman, \& H. Cuyckens (Eds.), Change of Paradigms - New Paradoxes (pp. 47-80). Berlin - München - Boston: De Gruyter Mouton.

Gow, A. S. F. (Ed.). (1952). Theocritus (Vol. 1; $2^{\text {nd }}$ ed.). Cambridge: Cambridge University Press.

Heine, B., Claudi, U., \& Hünnemeyer, F. (1991). From cognition to grammar: Evidence from African languages. In E. C. Traugott, \& B. Heine (Eds.), Approaches to grammaticalization (Vol. 1; pp. 149-187). Amsterdam: Benjamins.

Hock, H. (1991). Principles of Historical Linguistics. Berlin - New York: De Gruyter Mouton.

Hopper, P. J. (1991). On some principles of grammaticization. In E. C. Traugott, \& B. Heine (Eds.), Approaches to Grammaticalization (Vol. 1; pp. 17-35). Amsterdam: Benjamins.

Janda, M. (2000). Eleusis. Das indogermanische Erbe der Mysterien. Innsbruck: Institut für Sprachwissenschaft.

König, E., \& Traugott, E. C. (1988). Pragmatic strengthening and semantic change: the conventionalizing of conversational implicature. In W. Hüllen, \& R. Schulze (Eds.), Understanding the Lexicon: Meaning, Sense and World Knowledge in Lexical Semantics (pp. 110-124). Tübingen: Niemeyer.

Langacker, R. W. (1977). Syntactic Reanalysis. In C. N. Li (Ed.), Mechanisms of syntactic change (pp. 57-139). Austin: University of Texas Press.

Liddell, H. G., Scott, R., \& Jones, H. S. (1996). A Greek-English lexicon [= LSJ] (9 $9^{\text {th }}$ ed.). Oxford: Clarendon Press.

Littré, É. (Ed.). (1853, repr. 1962). Oeuvres complètes d'Hippocrate, vol. 8. Paris: Baillière (repr. Amsterdam: Hakkert). 
Lorimel, W. L. (Ed.). (1933). Aristotelis qui fertur libellus de mundo. Paris: Les Belles Lettres.

Masliš, M. (forthcoming). Formal opacity and semantic (in)stability of derived nominal lexemes in Ancient Greek.

Mathesius, V. (1966). Řeč a sloh. Praha: Československý spisovatel.

Murray, A. T. (Ed. \& Transl.). (1919). Odyssey (2 Vols.). London: W. Heinemann.

Nikolaev, A. (2012/2013). Homeric ảáatoc: Etymology and Poetics. Die Sprache, 50(2), 182-239.

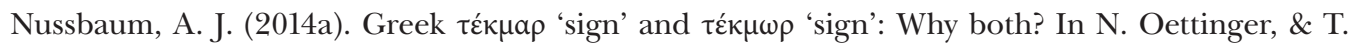
Steer (Eds.), Das Nomen im Indogermanischen (pp. 215-260). Wiesbaden: Reichert.

Nussbaum, A. J. (2014b). The PIE Proprietor and His Goods. In H. C. Melchert, E. Rieken, \& T. Steer (Eds.), Munus amicitiae Norbert Oettinger a collegis et amicis dicatum (pp. 228-254). Ann Arbor: Beech Stave Press.

Nussbaum, A. J. (2017). Agentive and other derivatives of "tó D. Petit, \& G.-J. Pinault (Eds.), Verbal adjectives and participles in Indo-European languages (pp. 233-266). Bremen: Hempen.

Oxford English Dictionary Online. (2021). Oxford University Press [accessible at https://www.oed. com/].

Probert, P. (2006). Ancient Greek Accentuation: Synchronic Patterns, Frequency Effects, and Prehistory. Oxford: Oxford University Press.

Pustejovsky, J. (1995). The Generative Lexicon. Cambridge, MA: MIT Press.

Ramscar, M., Yarlett, D., Dye, M., Denny, K., \& Thorpe, K. (2010). The effects of feature-label-order and their implications for symbolic learning. Cognitive science, 34(6), 909-957.

Reitzenstein, R. (1905). Etymologika. In Paulys Realencyclopädie der classischen Altertumswissenschaft (RE; Band V,2; pp. 807-817). Stuttgart: Metzler.

Rix, H., \& Kümmel, M. (2001). Lexikon der indogermanischen Verben ( $2^{\text {nd }}$ ed.). Wiesbaden: Reichert.

Sandell, R. P. (2015). Productivity in Historical Linguistics: Computational Perspectives on Word-Formation in Ancient Greek and Sanskrit. Ph.D. Diss., University of California.

Schreuder, R., \& Baayen, H. R. (1995). Modeling morphological processing. In L. B. Feldman (Ed.), Morphological Aspects of Language Processing (pp. 131-154). Mahwah, NJ.: Lawrence Erlbaum Associates.

Snell, B. et al. (Eds.). (1955-2010). Lexikon des frühgriechischen Epos [= LfgrE]. Göttingen: Vandenhoeck \& Ruprecht.

Štekauer, P. (2005a). Onomasiological Approach to Word Formation. In P. Štekauer, \& R. Lieber (Eds.), Handbook of word formation (pp. 207-232). Dordrecht: Springer.

Štekauer, P. (2005b). Meaning predictability in word formation. Novel, context-free naming units. Amsterdam - Philadelphia: John Benjamins.

Thompson, S. (1955-1958). Motif-index of folk-literature: a classification of narrative elements in folktales, ballads, myths, fables, mediaeval romances, exempla, fabliaux, jest-books, and local legends. Bloomington: Indiana University Press.

Tichy, E. (1983). Onomatopoetische Verbalbildungen des Griechischen. Wien: Österreichische Akademie der Wissenschaften.

Traugott, E. C. (2017). Semantic Change. Oxford Research Encyclopedia of Linguistics [retrieved 11.04.2021 from https://doi.org/10.1093/acrefore/9780199384655.013.323]. 
Traugott, E. C., \& Dasher, R. B. (2002). Regularity in semantic change. Cambridge: Cambridge University Press.

Valera, S. (2020). Polysemy Versus Homonymy. Oxford Research Encyclopedia of Linguistics [retrieved 11.04.2021 from https://doi.org/10.1093/acrefore/9780199384655.013.617].

Wendel, C. (Ed.). (1974). Scholia in Apollonium Rhodium Vetera ( $3^{\text {rd }}$ ed.). Berlin: Weidmann.

West, M. L. (Ed.). (1998). Homerus: Ilias. Rhapsodiae I-XII. Berlin - Boston: B. G. Teubner.

West, M. L. (Ed.). (2017). Homerus: Odyssea. Berlin - Boston: De Gruyter.

West, M. L. (Ed.). (2019). Homerus: Ilias. Rhapsodiae XIII-XXIV. Indices. Berlin - Boston: B. G. Teubner.

Mgr. Martin Masliš / martin.maslis@ff.cuni.cz

Institute of Greek and Latin Studies

Charles University, Faculty of Arts

Nám. Jana Palacha 2, 11638 Praha 1, Czech Republic 
